\title{
Experimental study on the mechanical interaction between silicon neural microprobes and rat dura mater during insertion
}

\author{
Z. Fekete ${ }^{1}$, A. Németh ${ }^{2}$, G. Márton ${ }^{3}$, I. Ulbert ${ }^{3,4}$, A. Pongrácz ${ }^{1}$ \\ ${ }^{1}$ MEMS Lab, Institute for Technical Physics \& Material Science, RCNS, HAS \\ P.O.Box 49, H-1525 Budapest, Hungary \\ ${ }^{2}$ Budapest University of Technology \& Economics, 3 Mủegyetem rkp., H-1111 Budapest, Hungary \\ ${ }^{3}$ Institute of Cognitive Neuroscience and Psychology, RCNS, HAS \\ P.O.Box 398, H-1394 Budapest, Hungary \\ ${ }^{4}$ Faculty of Information Technology, Pázmány Péter Catholic University \\ P.O.Box 278, H-1444 Budapest, Hungary \\ E-mail: fekete.zoltan@ttk.mta.hu
}

\begin{abstract}
In vivo insertion experiments are essential to optimize novel neural implants. Our work focuses on the interaction between intact dura mater of rats and as-fabricated single-shaft silicon microprobes realized by deep reactive ion etching.

Implantation parameters like penetration force and dimpling through intact dura mater were studied as a function of insertion speed, microprobe cross-section, tip angle and animal age. To reduce tissue resistance, we proposed a unique sharpening technique, which was also evaluated through in vivo insertion tests.

By doubling the insertion speed (between 1.2 and $10.5 \mathrm{~mm}$ per minute), an increase of 10-35\% in penetration forces was measured. When decreasing the cross-section of the microprobes, penetration forces and dimpling can be reduced by as much as $30-50 \%$ at constant insertion speeds. Force is gradually deceasing by decreasing tip angles. Measured penetration forces through dura mater were reduced even down to $11 \pm 3 \mathrm{mN}$ compared to unsharpened $(49 \pm 13 \mathrm{mN}$ ) probes by utilizing our unique probe sharpening technique, which is very close to exerted penetration force in the case of retracted dura $(5 \pm 1.5 \mathrm{mN})$.

Our findings imply that age remarkably alters the elasticity of intact dura mater. The decreasing stiffness of dura mater results in a significant rise in penetration force and decrease in dimpling.

Our work is the first in vivo comparative study on microelectrode penetration through intact and retracted dura mater.
\end{abstract}

Keywords: silicon microelectrodes; deep reactive ion etching; MEA tip sharpening; tissue penetration; insertion mechanics; tissue dimpling; insertion force; dura mater

\section{Introduction}

Interaction between brain tissue and neural microelectrodes is influenced by the conditions of surgery, the implantation method and geometric properties of the inserted device defined by fabrication methods . During medical implantations, neural microelectrodes are exposed to great loads 
as puncturing dura mater [Najafi, 1990]. On the other hand, the possible removal of dura is not advantageous, since inserted probes may fail due to regeneration or local infectious reactions. Dimpling of brain tissue is considered as a significant issue because of traumatic brain injury (TBI). ). TBI leads to cell death in case of thraumatic impacts on brain tissue (e.g. compression). When dimpling is relatively great, transport through capillary vessels to cortical cells stops. Since these cells do not have any supplementary resource to function, but only blood, even a short period (1-2 minutes) of circulation disorder results in irreversible damages and poor gain of neuronal activity during electrophysiological measurements [Rennaker, 2005]. Eventually, compromise between microprobe stability and reduction of tissue trauma is to be considered. Robust microprobes can withstand large forces, but cause considerable damage [Szarowski, 2003]. Previous experiments have demonstrated that removal of dura and pia mater reduces tissue resistance [Sharp, 2009], however, a mechanical characterisation of tissue-microprobe interaction has been not investigated in details through intact dura and pia mater so far. Moreover, in vivo analysis provides more significant data compared to in situ and ex vivo implantations as an earlier report of Gefen [Gefen, 2004] suggested. As Van Noort [Van Noort, 1981] and Gefen [Gefen, 2003] proved in the case of human and rat brain tissues respectively, the biomechanical behaviour of dura mater is age-dependent, which should be also considered in in vivo experiments.

The introduction of MEMS (Micro-Electro-Mechanical Systems) technology significantly standardized the fabrication of microprobes with well-defined probe shafts and precise placement of recording sites [Najafi, 1997]. The evolution of microfabrication techniques apparently influences the implantation parameters as well [Aggarwal, 2004]. The length, cross-section and tip of a microprobe are key geometric properties regarding mechanical stability. Generally, large cross-sectional area induces large tissue resistance during penetration [Davis, 2004], and small tip angle makes the insertion less invasive [Misra, 2008]. As regards the choice of materials, several structural polymers like SU-8 [Tijero, 2009] or polyimide [Cheung, 2007] are in the focus of neural probe designers, howver, silicon is still the dominant substrate for micromachining of neural microelectrodes [Hajjhassan, 2008; Scott 2012]. Despite, only a few attempts have been made to thoroughly characterize single-shaft microprobes fabricated by DRIE technology from the point of view of in vivo insertion mechanics. Some groups compared single and multi-shaft individual silicon microelectrodes to microprobes fabricated from several materials [Jensen, 2006; Hosseini 2007]. Nevertheless, the fabrication of silicon probes is increasingly supported by deep reactive ion etching techniques [Spieth, 2011; Seidl, 2011], therefore investigating the feasibility of this microprobe technology is of great importance. Previous reports provided valuable statistical data on insertion mechanics of DRIE etched silicon shafts, however, like in previous experiments, layers of dura mater were removed before implantation [Welkenhuysen, 2011; Andrei, 2012]. The only preliminary data on probe penetration with intact and retracted dura is presented by Sharp et al (Sharp, 2009) and Hosseini et al. (Hosseini, 2007), but no dependencies on geometry and implantation parameters were performed. Moreover, a systematic test on the effect of animal age was still not analyzed so far according to our knowledge.

As regards insertion methods, manually supported penetration of microprobes is usually performed. On the other hand, a controlled way of implantation can protect tissue from harsh impact [Johnson, 2007]. Pneumatic [Rousche, 1992] and spring-loaded [Bai, 2000] inserters can expose dura to moderate loads; however, they cannot offer further and controlled movement inside the brain tissue after penetration. Linear stepper motors and microdrives have been applied several times to overcome this issue [Cham, 2004; Fee, 2001; Paralikar, 2008; Welkenhuysen, 2011; Andrei, 2012;]. In our work, 
a large range is investigated between 1.2 and $10.5 \mathrm{~mm}$ per minute speed values reached by linear stepping.

In this work, silicon microprobes are tested in vivo through intact dura mater in order to reveal relationships between implantation parameters and geometric design of uncoated DRIE micromachined microprobes. We believe that results of our experiments serve as a good basis for the implantation of future robust microprobes not only in rodents, but as the chosen range of probe dimension indicates, in cats or apes as well.

\section{Experimental}

\subsection{Surgery}

Nine 2 and 12 months old Sprague Dawley rats were used for in vivo penetration experiments. All procedures were conducted according to the Animal Care Regulations of the Institute of Cognitive Neuroscience and Psychology, Research Centre for Natural Sciences, Hungarian Academy of Sciences. A mixture of $75 \mathrm{mg} / \mathrm{kg}$ ketamine and $10 \mathrm{mg} / \mathrm{kg}$ xylazine at was applied as initial anaesthesia via intraperitoneal injection. The body temperature was maintained at $37{ }^{\circ} \mathrm{C}$ throughout the penetration experiments. Animals were mounted in a stereotaxic frame and and a craniotomy with a diameter of 4 $\mathrm{mm}$ was performed. Dural surface was cleaned by sterile saline and was left intact, and it served as reference point for calculating the penetration depth. We used Bregma for the determination of the anterioposterior (AP) and mediolateral (ML) locations of the implantations. Implantation sites were randomly selected in rectangular areas (corner parameters are defined in Table 1.). Ventricles were avoided along the implantation tracks. Both left and right hemispheres were used, since both of them are considered similar in terms of tissue mechanics. A maximal number of seven insertions from at least $1 \mathrm{~mm}$ distance from one another were performed per hemisphere in order to minimize parasitic phenomena and the number of sacrificed animals. At the end of each experiment, animals were sacrificed by overdosing the mixture of ketamine/xylazine.

\subsection{Microfabrication}

4" (100) oriented Si double-side polished wafers were used for the fabrication of dummy microprobes. Fabrication sequence is illustrated in Fig 2.a Evaporated Al thin film patterned by photolithography was used as a masking layer on the front side, while the etch stop layer consisted of a spin-coated photoresist and evaporated Al stack on the backside of the wafer (step 1). Probe shafts were formed by through-wafer etch using Bosch process of deep reactive ion etching (DRIE) performed in an Oxford Plasmalab System 100 chamber (step 2). Finally, masking layers were removed (step 3). Geometric parameters of the realized probes are detailed in Section 2.4. Varied probe tips of our samples are illustrated by Fig. 1.a-d.

\subsection{Probe sharpening method}

Alkaline-based wet chemical etchants (like $\mathrm{KOH}, \mathrm{NaOH}$, TMAH, EDP) show different etch rate in different crystallographic directions of the single crystalline silicon lattice. The etch rate of (111) crystallographic plane is several hundred times lower than that of (100) plane resulting in typical shapes like V-trenches or inverse pyramids. Vázsonyi et al. found that such alkaline solutions 
containing strong oxidation agent $(\mathrm{NaOH} / \mathrm{NaOCl}$ system) differ in etching mechanism [Vázsonyi, 2003]. They observed a decrease in anisotropy from 100 to $4-6$, which is caused by the presence of two different oxidation mechanisms [Vázsonyi, 2007]. The following beneficial features were observed during the application of the above etchant mixture. Because of the low anisotropy, the local defect development is not significant, which results in smooth surfaces. Vertically etched walls can be formed with mask sidelines aligned parallel to the $\langle 100\rangle$ direction. In our work, this etching mechanism has been utilized subsequently after the preliminary formation of microprobes by deep reactive ion etching. Applying this combined etching process we can characterise the effects of wet chemical sharpening of the DRIE pre-etched probes. Sample A0 stands for the reference micromachined by DRIE only. Sample $A_{\text {ref }}$ is equivalent to A0 in all geometric parameter, however, all respective measurement is carried out with retratcted dura. A1 and A2 represent variants fabricated by the proposed combined etching process. Fabrication schematics are shown in Fig. 2.b. In the case of sample A1, a $20 \mu \mathrm{m} \mathrm{Si} \mathrm{membrane} \mathrm{remained} \mathrm{after} \mathrm{a} \mathrm{preliminary} \mathrm{dry} \mathrm{etching} \mathrm{(Bosch} \mathrm{process).} \mathrm{A}$ subsequent alkaline etching in $\mathrm{NaOH} / \mathrm{NaOCl}$ bath [Vázsonyi, 2003] with a $\mathrm{SiN}_{\mathrm{x}}$ front-side masking was performed $(t=240 \mathrm{~min})$, which released the microprobes completely and resulted in sharp tips. In the case of sample A2, these key fabrication parameters were $30 \mu \mathrm{m}$ and $120 \mathrm{~min}$, respectively. The final cross-section of the shafts of A1 and A2 after the proposed combined etching process is $500 \mu \mathrm{m} x$ $100 \mu \mathrm{m}$ (same as A0) also illustrated by SEM micrographs in Fig. 3.

\subsection{Measurement setup \& experimental design}

Microprobes were fixed in a custom-designed holder, which was attached to an Andilog Centor Easy type force gauge (measurement limit: $10 \mathrm{~N}$, resolution: $1 \mathrm{mN}$ ). Finally, this setup was mounted on a stereotaxic platform. The vertical position of the probes was adjusted by a Gamma type stepper motor $\left(1.8^{\circ}\right.$ step angle). The measurement setup for in vivo insertion is shown in Fig. 4. Stepping units was $10 \mu \mathrm{m}$, while stepping precision was $1 \mu \mathrm{m}$. Data acquisition was performed by a Labview controlled measurement system including a NI digital I/O card. Sampling rate was synchronised to the actual stepping frequency of the linear motor. Noise level of our insertion system was approximately $1 \mathrm{mN}$. Insertions were performed at permanent speed values (between 1.2 and $10.5 \mathrm{~mm}$ per minute). The recorded data was post-process by a fourth-order Butterworth low-pass filter implemented in a MatLab code. Before each insertion, the probes mounted on the load cell covered a distance of $1 \mathrm{~mm}$ until being in physical contact with the tissue surface in order to record a baseline. The probe tip was considered to reach the surface of dura, when the measured force values exceeded the noise level of the insertion system. The measurement of dimpling starts at this point and lasts until dura is punctured. This maximum recorded force is defined as the penetration force necessary to puncture the tissue. A representative force vs. depth curve after signal filtering is shown in Fig. 5. Tissue relaxation phase shows additional small peak loads, which can be attributed to the increasing interfacial area of the probe being in contact with the surrounding tissue. Fracture of the probes was not observed during insertion experiments. Table 2 gives an overview of the experimental design including investigated probe geometries and insertion parameters.

\section{Results \& Discussion}

\subsection{Effect of insertion speed}


Penetration force was analysed at several insertion speed values. Respective data is presented in Fig. 6. We concluded that increase in the insertion speed induces a gradual increase in forces acting on the probe tip. Doubling the insertion speed in the analyzed regime, an increase of $10-35 \%$ in penetration forces was measured. A much faster insertion may provide less tissue resistance and easier penetration [Bjornsson, 2006]. In the case of actuation by a linear stepper motor in the analyzed regime this statement does not apply. Such observation was reported by other authors [Andrei, 2012; Welkenhuysen, 2011], which proved the steady increase in maximum forces as speed increased. Dimpling was also determined plotted against insertion speed. Characteristic dependence of dimpling on speed was not observed in the analyzed regime. The same behaviour was found when dura is removed [Andrei, 2012]. It should be noted that pneumatic [Rousche, 1992] or spring-loaded [Johnson, 2007] insertion devices provide significantly lower dimpling than microdrives, but the implantation speed regime proposed here is far exceeded in those cases. The presence of dura mater remarkably changed the measured force values, which is in well agreement with an earlier report [Sharp, 2009]. Similar insertion tests conducted by a microdrive in the same speed regime with retracted dura [Andrei, 2012] provided penetration forces more than ten times smaller compared to our data.

\subsection{Effect of probe cross-section}

Regarding microprobe geometry, samples of high interfacial area induce high penetration forces [Davis, 2004]. When decreasing the cross-section of the microprobes by a factor of four, penetration forces and dimpling values were reduced by as much as 30-50\% at constant insertion speeds (see Table 3). A similar relationship was reported previously on tungsten wires of cylindrical shape [Sharp, 2009], on parlyene C coated Si probes [Andrei, 2012], and on ACREO Si probes probes [Jensen, 2006], all deriving from implantations through retracted dura mater. It is clearly shown that increase in interfacial area of the microprobes has a disadvantageous effect on tissue resistance. Difference in mechanical behaviour between samples denoted by '200x400' and '400x200' suggests that edge length of the tip of the probes tailors the magnitude of exerted pressure in case of probes with identical cross-sections. This also implies that wider probes, which provide larger active surface for the integration of functional microdevices, are probably less invasive than other probes of reduced width, and fabricated from thicker wafers. In this regards, no literature data exists, however, additional histological tests are definitely necessary to confirm this finding.

\subsection{Effect of tip angle \& sharpening}

Limiting stretches and compression of the tissue during insertion may result in less cell damage [Edell, 1992]. A reasonable way to reduce tissue resistance is to reduce tip angle [Misra, 2008] or sharpen original probe shapes by chemical methods [Grand, 2011]. On the other hand, the reduction of tip angle is limited, since fracture forces are reduced due to the deflection caused by asymmetry in probe cross-section [Abolhassani, 2007]. Table 4 summarizes the effect of tip angle on the insertion parameters. It suggests that a force values gradually decreases by decreasing tip angles. Dimpling is only moderately influenced. Same conclusions have been reported by other studies focused on the cases when dura mater is removed [Andrei, 2012]. The measured penetration forces of our chemically sharpened microprobes A1 and A2 including data on unsharpened references are summarized in Table 5. According to the results, the subsequent tip sharpening of DRIE fabricated probes reduces tissue resistance by almost $80 \%$, to a value $(11 \pm 3 \mathrm{mN})$ very close to exerted penetration force in the case of retracted dura $(5 \pm 1.5 \mathrm{mN})$. The advantage of the proposed fabrication method is that probe crosssection remains rectangular and no asymmetric distribution of lateral forces is acting on the probe. 
Therefore no buckling $\left(\mathrm{F}_{\text {critical }}=223 \mathrm{mN}\right)$ is experienced during in-vivo insertions. Furthermore, the smoothing of scalloped sidewall profile, which is inherently produced by high aspect ratio Si etching using Bosch process [Jansen, 1997], may reduce frictional forces during both tissue relaxation or vertical probe positioning [Andrei, 2012]. Eventually, the penetration force experienced by applying our sharpened microprobe A2 is only two or three times higher than that of other microprobes with similar cross-sections and punctured through retracted dura [Welkenhuysen, 2011; Andrei, 2012]. It is remarkable, since dura layers were not removed during our surgery. On the other hand, our unsharpened samples induced a difference in average penetration forces as much as one order of magnitude compared to studies with retracted dura mater.

\subsection{Effect of rodent's age}

Gefen et al. [Gefen, 2003] compared the elastic properties of young (at postnatal time around two weeks) and old (1.5-3 months) rat brain tissue. They reported that immature brain tissue was significantly stiffer. Another study showed that mean average residual strain in the dura mater of immature rats (postnatal time between 2-26 days) are higher by on order of magnitude than that of mature rats (around 3 months old) [Henderson, 2005]. The results of our experiments conducted with rats of similar age is represented by Fig. $7 \mathrm{a} \& \mathrm{~b}$. Average penetration forces have changed by as much as $50 \%$ in the case of probe cross-section '200x200'. However, the increase of penetration force by age is obvious; dimpling is reduced to the same extent at each tested cross-section. It is known that thickness of dura is increasing as a function of age, which obviously contributes to the elevated stiffness. Nevertheless, the elasticity of brain tissue inherently influences our results; therefore the mechanical properties of dura mater cannot be independently evaluated. Only a combined effect of dura mater and underlying tissue can be considered in our case. On the other hand, trends in our results are in agreement of similar investigations in the literature focusing on the age-dependent elastic properties [Gefen, 2003; Henderson, 2005], which suggests that age and therefore the residual strain in dura mater of immature sacrificed animals significantly contributes the elevated mechanical resistance to probe penetrations as well.

\section{Conclusion}

In this work, the mechanical interaction of rat brain tissue and silicon microprobes fabricated by deep reactive ion etching was characterised by in vivo penetration tests using a linear stepper motor to maintain various insertion speeds. Penetration force and dimpling were measured through intact dura mater and evaluated in the case of microelectrode dummies featured by various cross-sections and tips. The increase in insertion speed between 1.2-10.5 mm per minute induced an increase in the average penetration force. By doubling the insertion speed in the analyzed regime, an increase of $10-35 \%$ in penetration forces was measured. Dimpling is not affected by speed. Both of these trends are in this value is in agreement with other reported experiments with retracted dura. When decreasing the crosssection of the microprobes, penetration forces and dimpling values can be reduced by as much as 30$50 \%$ at constant insertion speeds. This change is comparable to that experienced by other authors when dura was retracted. The effect of tip angle on the insertion parameters suggests that force values are gradually deceasing with decreasing tip angles, however, the relationship is more remarkable compared to cases of removed dura. Dimpling was observed to be moderately influenced by tip angle.

As far as we know, our in vivo experiments are the first that reveal dependency of force and dimpling on animal age in the case of intact dura mater. Our findings in this regards are in agreement with 
investigations in the literature focusing on elastic properties. This implies that age remarkably alters the elasticity of intact dura mater, and eventually results in a significant rise in penetration force. On the other hand, a decrease in dimpling can be expected by age due to the increasing stiffness and thickness of dura mater. We also described a tip sharpening method for microprobes fabricated by DRIE. Our study showed that subsequent wet etching of DRIE etched probes offers a remarkable reduction in penetration force even down to $11 \pm 3 \mathrm{mN}$ compared to unsharpened $(49 \pm 13 \mathrm{mN})$ probes by utilizing our unique probe sharpening technique. This value is very close to the exerted penetration force in the case of retracted dura $(5 \pm 1.5 \mathrm{mN})$, which proves that our proposed technique makes preliminary incisions before insertions unnecessary.

\section{Acknowledgements}

The authors are grateful to the supportive staff of MEMS Lab, Research Centre for Natural Sciences. A. Pongrácz is thankful for the Bolyai János Grant of the HAS. Z. Fekete is supported by the Postdoctoral Research Programme of the HAS. This research was supported by the Hungarian Science Foundation (OTKA K81354) to I. Ulbert.

\section{References}

Abolhassani, N., Patel, R., Moallema, M., 2007. Needle insertion into soft tissue: A survey. Med. Eng. \& Phys. 29, 413-431.

Aggarwal, P., Johnston, C.R., 2004. Geometrical effects in mechanical characterizing of microneedle for biomedical applications. Sens. \& Act. B 102, 226-234.

Andrei, A., Welkenhuysen, M., Nuttin, B., Eberle, W., 2012. A response surface model predicting in vivo insertion behaviour of micromachined neural implants. J. Neural Eng. 9, 016005.

Bai, Q., Wise, K. D., Anderson, D. J., 2000. A high-yield microassembly structure for threedimensional microelectrode arrays, IEEE Trans. Biomed. Eng. 47, 281-289.

Bjornsson, C. S., Oh, S. J., Al-Kofahi, Y. A., Lim, Y. J., Smith, K. L., Turner, J. N., De, S., Roysam, B., Shain, W., Kim, S. J., 2006. Effects of insertion conditions on tissue strain and vascular damage during neuroprosthetic device insertion. J. of Neural Eng. 3, 196-207.

Cham, J. G., Branchaud, E. A., Nenadic, Z., Greger, B., Andersen, R. A., Burdick, J. W., 2004. Semichronic motorized microdrive and control algorithm for autonomously isolating and maintaining optimal extracellular action potentials. J. of Neurophysiol. 93, 570-579.

Cheung, K.C., Renaud, P., Tanila, H., Djupsund, K., 2007. Flexible polyimide microelectrode array for in vivo recordings and current source density analysis, Biosens \& Bioelectron. 22, 1783-1790.

Davis, S. P., Landisa, B. J., Adams, Z. H., Allen, M. G., Prausnitz, M. R., 2004. Insertion of microneedles into skin: measurement and prediction of insertion force and needle fracture force. J. of Biomechanics 37, 1155-1163. 
Edell, D. J., Toi, V. V., McNeil, V. M., Clark, L. D., 1992. Factors influencing the biocompatibility of insertable silicon microshafts in cerebral cortex, IEEE Trans. Biomed. Eng. 39, 635-643.

Fee, M. S., Leonardo A., 2001. Miniature motorized microdrive and commutator system for chronic neural recording in small animals. J. of Neurosci. Meth. 112, 83-94.

Gefen, A., Gefen, N., Zhu, Q., Raghupathi, R., Margulies, S. S., 2003. Age-dependent changes in material properties of the brain and braincase of the rat. J Neurotrauma 11, 1163-77.

Gefen, A., Margulies, S. S., 2004. Are in vivo and in situ brain tissues mechanically similar? J. of Biomechanics 37, 1339-1352.

Genina, E. A., Bashkatov, A. N., Kochubey, V. I., Tuchin, V. V., 2005. Optical Clearing of Human Dura Mater, Optics and Spectroscopy 98, 470-476.

Grand L., Pongrácz, A., Vázsonyi, É., Márton, G., Gubán, D., Fiáth, R., Kerekes, B. P., Karmos, Gy., Ulbert I., Battistig, G., 2011. A novel multisite silicon probe for high quality laminar neural recordings, Sens. \& Act. A 166, 14-21.

Hajjhassan, M., Chodavarapu V., Musallam, S., 2008. NeuroMEMS: Neural Probe Microtechnologies. Sensors 8, 6704-6726.

Henderson, J. H., Nacamuli, R. P., Zhao, B., Longaker, M. T., Carter, D.R., 2005. Age-dependent residual tensile strains are present in the dura mater of rats, J. R. Soc. Interface 2, 159-167.

Hosseini, N. H., Hoffmann, R., Kisban, S., Stieglitz, T., Paul, O., Ruther, P., 2007. Comparative study on the insertion behaviour of cerebral microprobes. Conf. Proc. IEEE Eng. Med. Biol. Soc. 2007, 4711-4.

Jansen, H. V., de Boer, M. J., Wiegerink, R., Tas, N., Smulders, E., Neagu, C. Elwenspoek, M., 1997. RIE lag in high aspect ratio trench etching of silicon. Microelectr. Eng. 35, 45-50.

Jensen, W., Yoshida, K., Hofmann, U. G., 2006. In-vivo implant mechanics of flexible, silicon-based ACREO microelectrode arrays in rat cerebral cortex. IEEE Trans. Biomed. Eng. 53, 934-40.

Joucla, S., Rousseau, L., Yvert, B., 2012. Focalizing electrical neural stimulation with penetrating microelectrode arrays: A modelling study. J. of Neurosci. Meth. 209, 1-5.

Johnson, M. D., Kao, O. E., Kipke, D. R., 2007. Spatio temporal pH dynamics following insertion of neural microelectrode arrays. J. of Neurosci. Meth. 160, 276-287.

Misra, S., Reed, K. B., Douglas, A. S., Ramesh, K. T., Okamura, A. M., 2008. Needle-Tissue Interaction Forces for Bevel-Tip Steerable Needles. Proc. of the 2nd Biennial IEEE/RAS-EMBS Int. Conf. on Biomedical Robotics \& Biomechatronics, Scottsdale, USA.

Najafi K., 1990. Strength characterization of silicon microprobes in neurophysiological tissues. IEEE Tr. on Biomed. Eng. 37, $474-481$. 
Najafi, K., 1997. Micromachined systems for neurophysiological applications. In Handbook of Microlithography, Micromachining and Microfabrication II: Micromachining and Microfabrication. SPIE PRESS Monograph: London.

Paralikar, K. J., Clement, R. S., 2008. Collagenase-Aided Intracortical Microelectrode Array Insertion: Effects on Insertion Force and Recording Performance. IEEE Trans. Biomed. Eng. 55, 2258-2267.

Rennaker, R.L., Street, S., Ruyle, A.M., Sloan, A.M., 2005. A comparison of chronic multi-channel cortical implantation techniques: manual versus mechanical insertion. J. of Neurosci. Meth. 142, 169176.

Rousche, P. J., Normann, R. A., 1992. A method for pneumatically inserting an array of penetrating electrodes into cortical tissue. Annals of Biomed. Eng. 20, 413-422.

Szarowski, D. H., Andersen, M.D., Retterer, S., Spence, A.J., Isaacson, M., Craighead, H.G., Turner, J.N., Shain, W. , 2003. Brain responses to micro-machined silicon devices. Brain Research 983, 2335 .

Seidl, K., Herwik, S., Torfs, T., Neves, H. P., Paul, O., Ruther, P., 2011. CMOS-Based High-Density Silicon Microprobe Arrays for Electronic Depth Control in Intracortical Neural Recording. J. of Microelectromech. Syst. 20, $1439-1448$.

Scott, K. M., Du, J., Lester, H. A., Masmanidis, S. C., 2012. Variability of acute extracellular action potential measurements with multisite, J. of Neurosci. Meth. 211, 22-30.

Sharp, A. A., Ortega, A. M., Restrepo, D., Curran-Everett, D., Gall, K., 2009. In Vivo Penetration Mechanics and Mechanical Properties of Mouse Brain Tissue at Micrometer Scales. Trans. on Biomed. Eng. 56, 45-53.

Spieth, S., Brett, O. , Seidl, K., Aarts, A. A. A., Erismis, M. A., Herwik, S., Trenkle, F., Tatzner, S., Auber, J., Daub, M., Neves, H. P., Puers, R., Paul, O., Ruther, P., Zengerle, R., 2011. A floating 3D silicon microprobe array for neural drug delivery compatible with electrical recording. J. Micromech. Microeng. 21, 125001.

Tijero, M., Gabriel, G., Caro, J., Altuna, A., Hernández, R., Villa, R., Berganzo, J., Blanco, F.J., Salido, R., Fernández, L.J., 2009. SU-8 microprobe with microelectrodes for monitoring electrical impedance in living tissues, Biosens Bioelectron. 24, 2410-2416.

Van Noort, R., Martin, T. R. P., Black, M. M., Barker, A. T., Montero, C. G., 1981. The mechanical properties of human dura mater and the effects of storage media. Clin. Phys. Physiol. Meas. 2, 197.

Vázsonyi, É., Vértesy, Z., Tóth, A., Szlufcik, J., 2003. Anisotropic etching of silicon in a twocomponent alkaline solution. J. Micromech. Microeng. 13, 165-169.

Vázsonyi, É., Dücső Cs., Pekker, Á., 2007. Characterization of the anisotropic etching of silicon in two-component alkaline solution. J. Micromech. Microeng. 17, 1916. 
Welkenhuysen, M., Andrei, A. A., Ameye, L., Eberle W. and Nuttin B., 2011. Effect of Insertion Speed on Tissue Response and insertion mechanics of a chronically implanted silicon-based neural probe. IEEE Tr. on Biomed. Eng. 58, 3250-3259. 


\section{Figure captions}

Figure 1. SEM micrographs of DRIE micromachined probe tips with angles of $90^{\circ}$ (a), $60^{\circ}$ (b), $30^{\circ}$ (c) and sideview of a typical DRIE etched tip (d).

Figure 2. Process flows of microprobe fabrication including reference (A0) and sharpened samples (A1, A2). Micromachining steps are illustrated from the front view of the microprobes. Lateral view of the final probe tips are represented by Fig.1.b (A0) and Fig. 3 (A1 \&A2).

Figure 3. Microprobes A1 and A2 fabricated by deep reactive ion etching and sharpened by subsequent alkaline etching. Crystallographic planes are indicated by captions.

Figure 4. Schematic representation of the experimental setup for in vivo testing of penetration mechanics.

Figure 5. A representative force-distance curve measured in the case of probe cross-section $200 \mu \mathrm{m} x$ $200 \mu \mathrm{m}$ at an insertion speed of $1 \mathrm{~mm} / \mathrm{min}$. The definitions of dimpling and penetration force are also illustrated. The probe tip was considered to reach the surface of dura, when the measured force values exceeded the noise level of the insertion system. The measurement of dimpling starts at this point and lasts when dura is punctured, which happens at the highest recorded force, the penetration force.

Figure 6. Measured penetration force and dimpling at various penetration speeds in the case of probe cross-section $200 \mu \mathrm{m} \times 200 \mu \mathrm{m}$.

Figure 7. Penetration force (a) and dimpling (b) as a function of rodent age in the case of two different probe cross-sections.

\section{Table captions}

Table 1. Stereotactic coordinates representing the boundary corners of implanted areas on both hemisphere. AP and ML refers to anterioposterior and mediolateral locations with respect to Bregma, respectively.

Table 2. Overview of the experimental design

Table 3. Average values and standard deviation of measured penetration force and dimpling in the case of different probe cross-sections $(\mathrm{n}=10)$.

Table 4. Average values and standard deviation of measured penetration force and dimpling in the case of different tip angle $(n=4)$.

Table 5. Average values and standard deviation of measured penetration force of unsharpened (A0) and sharpened (A1, A2) microprobes $(\mathrm{n}=5)$. 
Figure 1

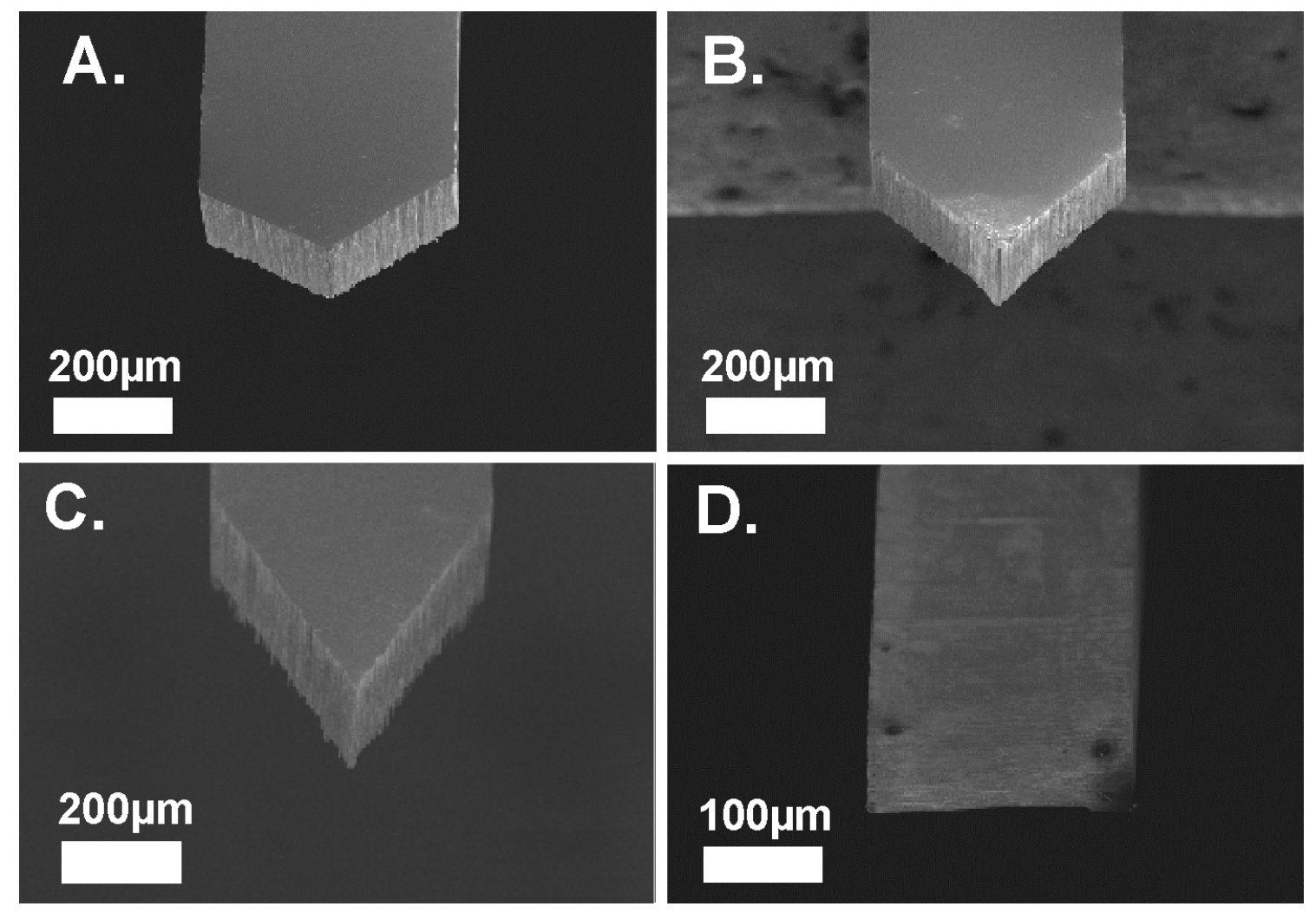


Figure 2

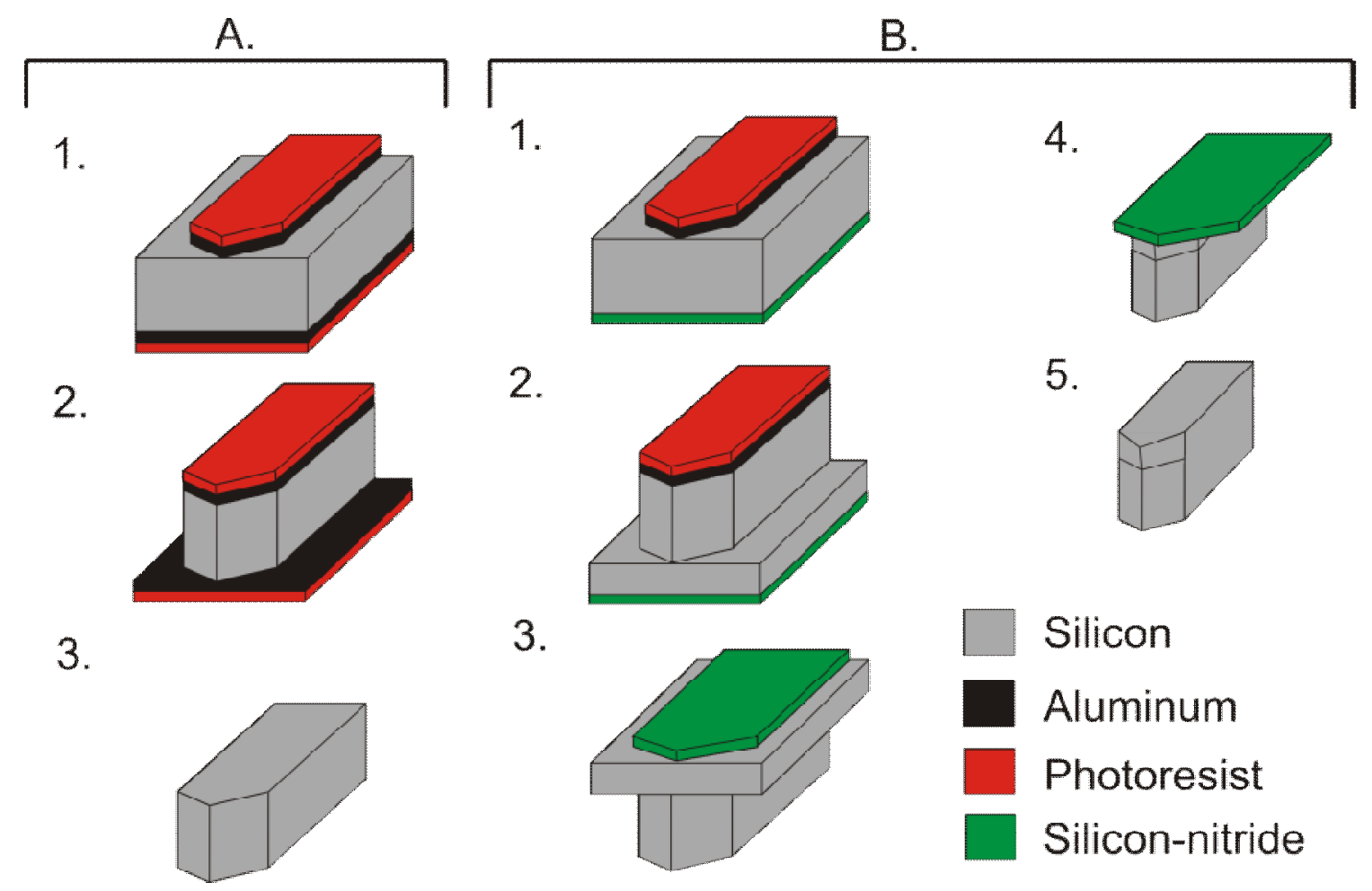


Figure 3
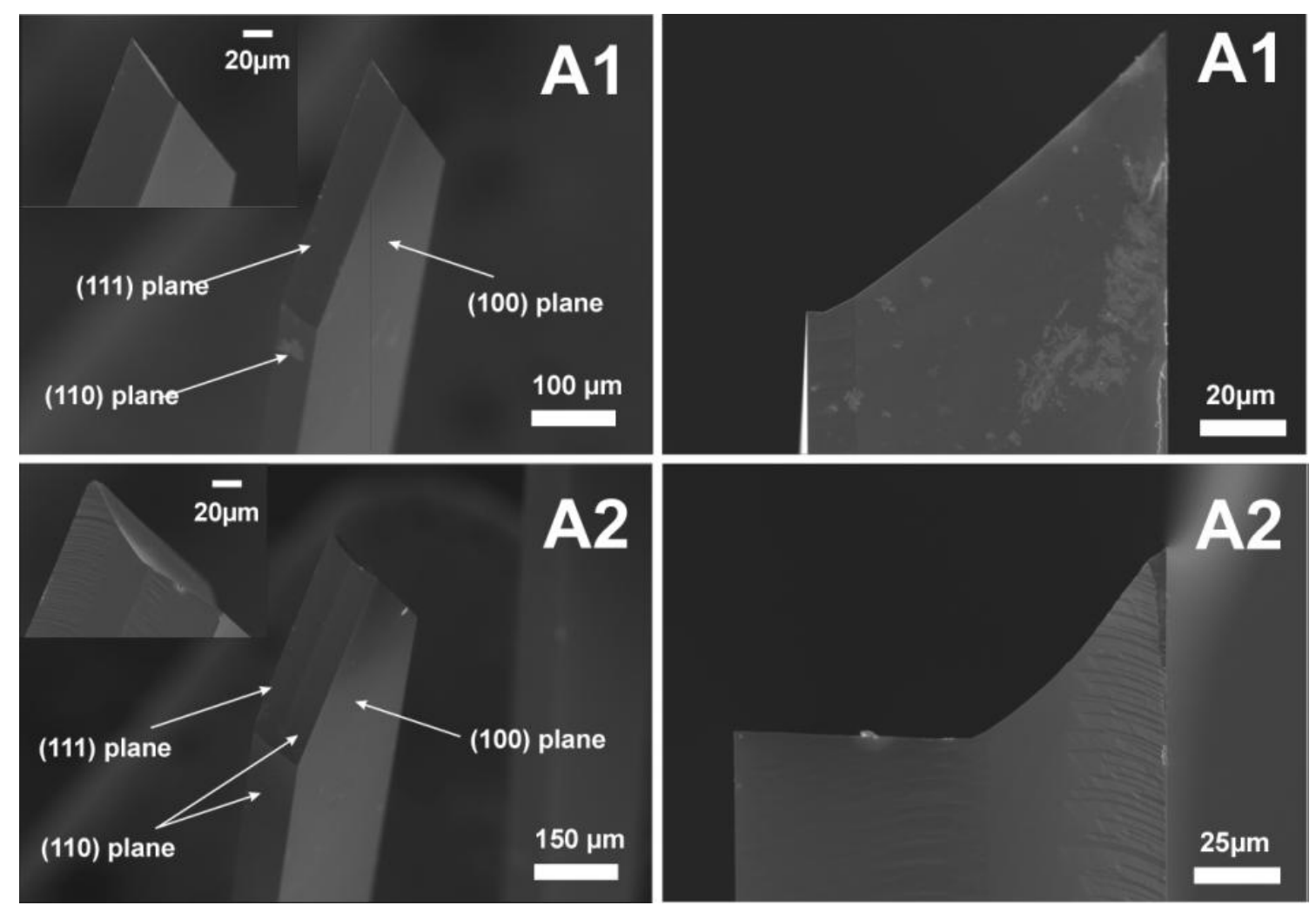
Figure 4

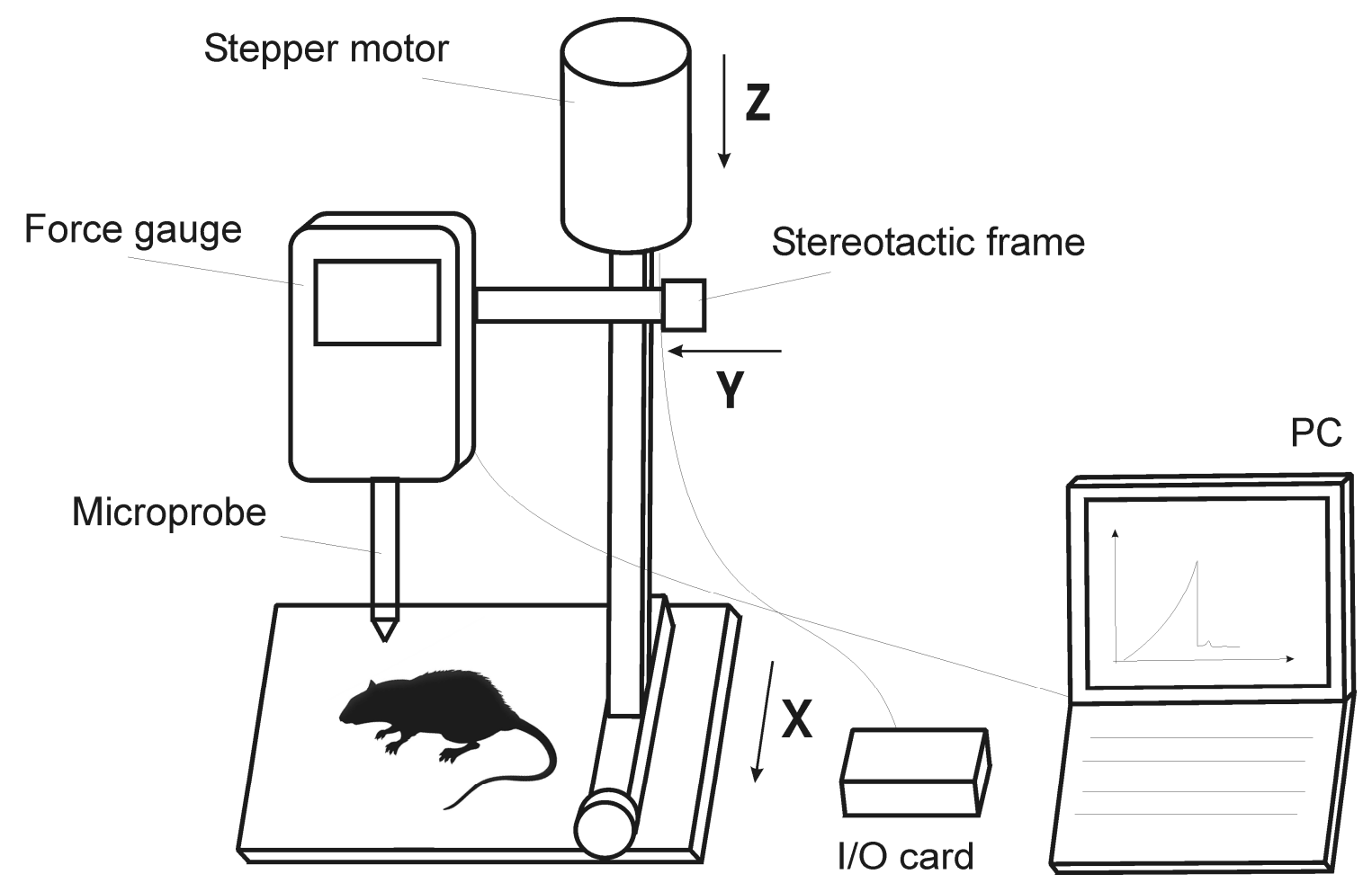


Figure 5

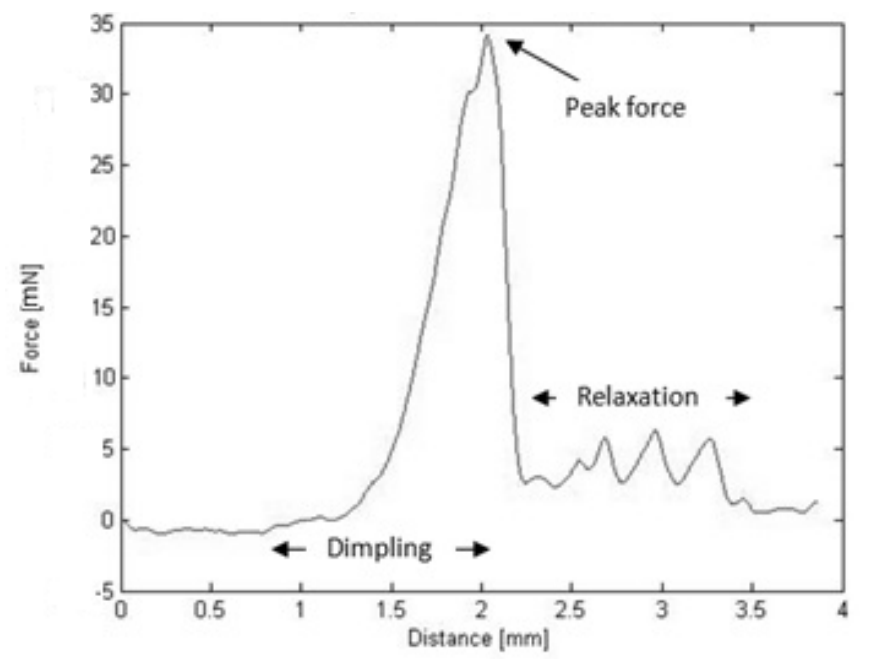


Figure 6

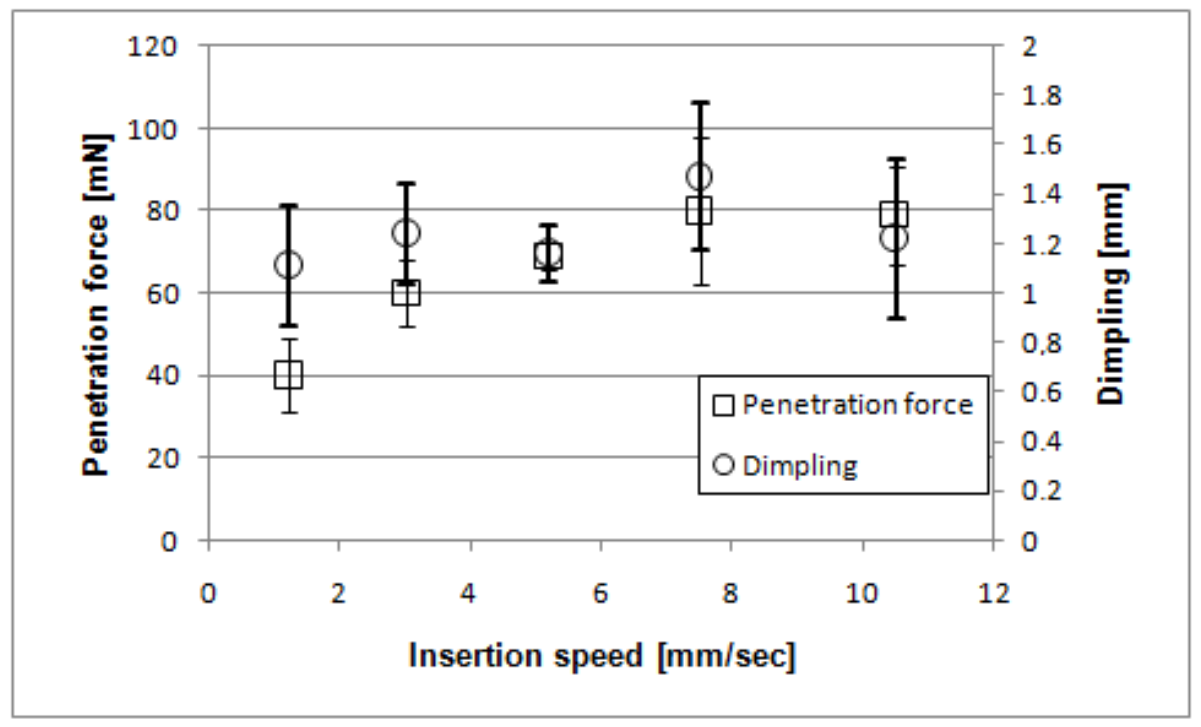


Figure 7

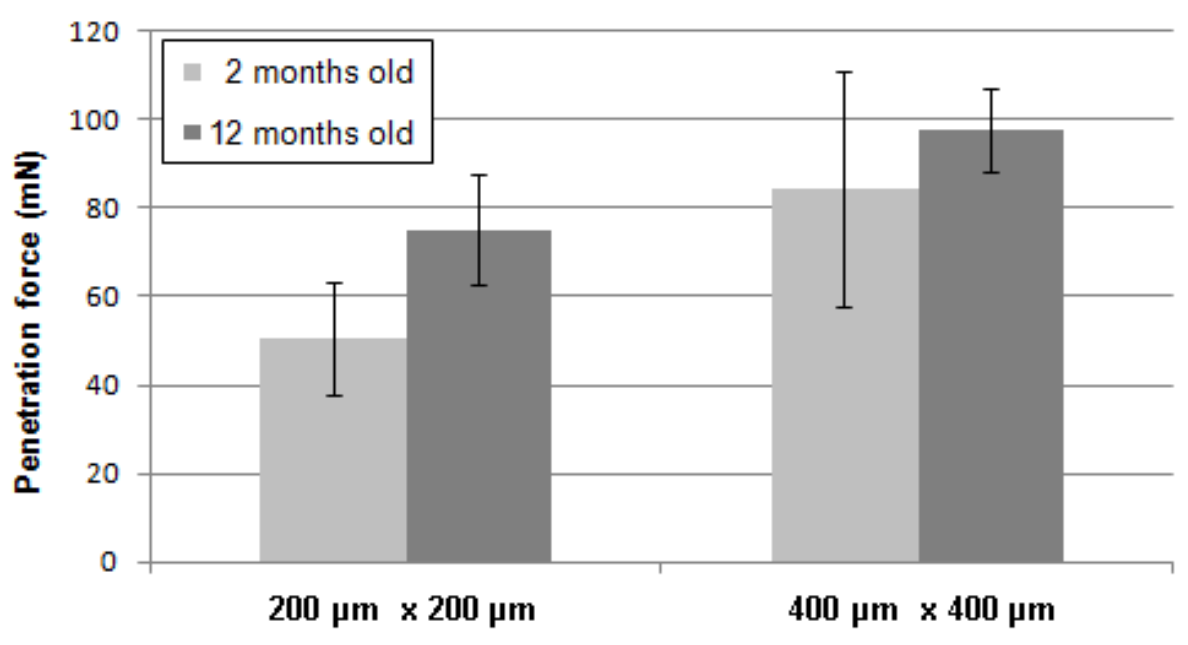

Probe cross-section (width $\mathrm{x}$ thickness) 
Figure 8

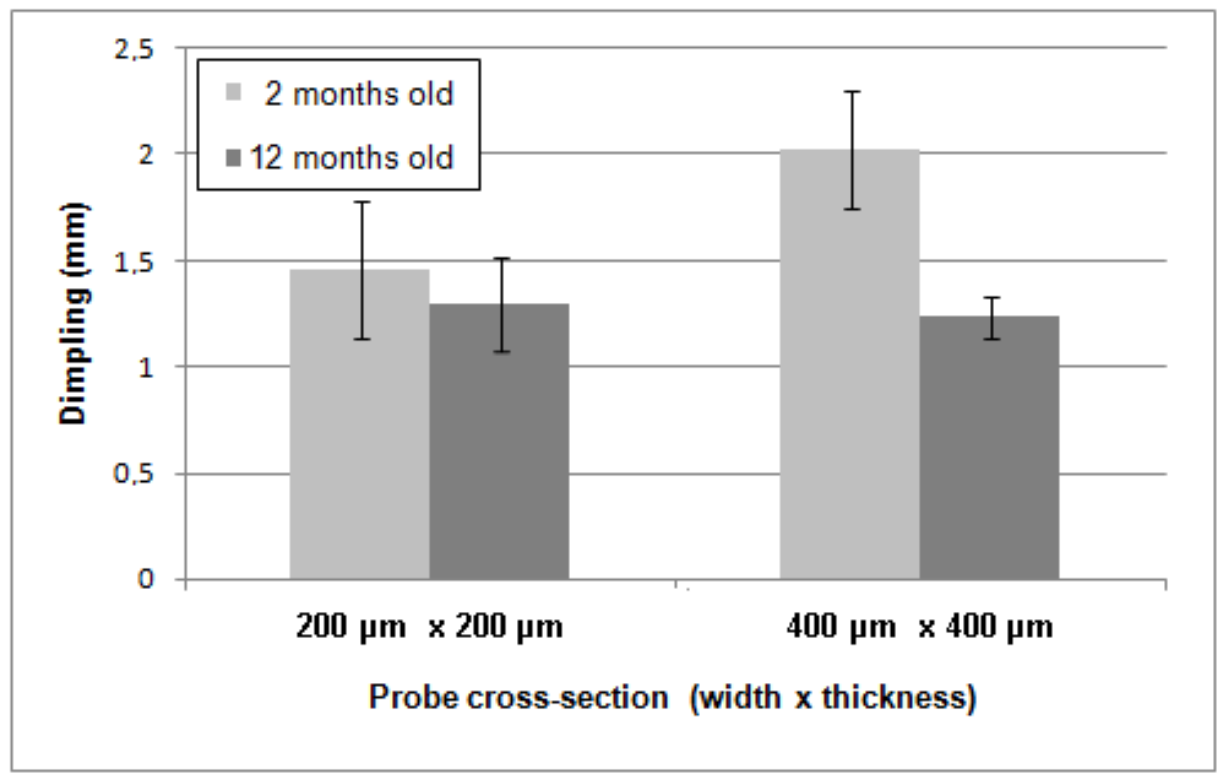


Table 1.

Coordinates relative to Bregma in the left hemisphere

\begin{tabular}{|c|c|c|}
\hline Corner & AP & $\mathrm{ML}$ \\
\hline 1 & -2.1 & -0.75 \\
\hline 2 & -2.1 & -2.75 \\
\hline 3 & -5.5 & -0.75 \\
\hline 4 & -5.5 & -2.75 \\
\hline
\end{tabular}

Coordinates relative to Bregma in the right hemisphere

\begin{tabular}{|c|c|c|}
\hline Corner & AP & $\mathrm{ML}$ \\
\hline 1 & -3.3 & 2 \\
\hline 2 & -3.3 & 4 \\
\hline 3 & -5.3 & 2 \\
\hline 4 & -5.3 & 4 \\
\hline
\end{tabular}

Table 2.

\begin{tabular}{|l|c|c|c|c|c|}
\hline \multicolumn{1}{|c|}{ Objectives } & $\begin{array}{c}\text { Shank } \\
\text { length } \\
(\mathbf{m m})\end{array}$ & $\begin{array}{c}\text { Shank } \\
\text { width } \mathbf{x} \\
\text { thickness }(\boldsymbol{\mu m} \\
\mathbf{x} \boldsymbol{\mu m})\end{array}$ & $\begin{array}{c}\text { Tip angle } \\
\left.\mathbf{(}^{\circ}\right)\end{array}$ & $\begin{array}{c}\text { No. of insertions } \\
\text { per data points }\end{array}$ & $\begin{array}{c}\text { Insertion } \\
\text { speed } \\
(\mathbf{m m} / \mathbf{m i n})\end{array}$ \\
\hline $\begin{array}{l}\text { Force vs. Speed; } \\
\text { Dimpling vs. Speed }\end{array}$ & 30 & $200 \times 200$ & 30 & 8 & $\begin{array}{c}1.2,3,5.2, \\
7.5,10.5\end{array}$ \\
\hline $\begin{array}{l}\text { Force vs. Cross- } \\
\text { sections; } \\
\text { Dimpling vs. Cross- } \\
\text { section }\end{array}$ & 30 & $\begin{array}{l}200 \times 200, \\
200 \times 400, \\
400 \times 200, \\
400 \times 400\end{array}$ & 30 & 10 & 3 \\
\hline $\begin{array}{l}\text { Force vs. Tip angle; } \\
\text { Dimpling vs. Tip angle }\end{array}$ & 7 & $400 \times 100$ & $30,60,90$ & 4 & 3 \\
\hline $\begin{array}{l}\text { Force vs. Sharpening } \\
\text { Force vs. Age; }\end{array}$ & 7 & $500 \times 100$ & 45 & 5 & 3 \\
\hline Dimpling vs. Age & 30 & $200 \times 200$, & 30 & 4 & \\
\hline
\end{tabular}


Table 3.

\begin{tabular}{|c|c|c|}
\hline $\begin{array}{c}\text { Shank width } \times \text { thickness } \\
(\mu \mathrm{m} \times \mu \mathrm{m})\end{array}$ & $\begin{array}{c}\text { Penetration force } \\
(\mathbf{m N})\end{array}$ & $\begin{array}{c}\text { Dimpling } \\
(\mathbf{m m})\end{array}$ \\
\hline $200 \times 200$ & $58 \pm 8$ & $1.06 \pm 0.2$ \\
\hline $200 \times 400$ & $70 \pm 10$ & $1.19 \pm 0.21$ \\
\hline $400 \times 200$ & $98 \pm 11$ & $1.56 \pm 0.12$ \\
\hline $400 \times 400$ & $93 \pm 2$ & $1.70 \pm 0.26$ \\
\hline
\end{tabular}

Table 4.

\begin{tabular}{|c|c|c|}
\hline Tip angle $\left(^{\circ}\right)$ & $\begin{array}{c}\text { Penetration force } \\
(\mathbf{m N})\end{array}$ & $\begin{array}{c}\text { Dimpling } \\
(\mathbf{m m})\end{array}$ \\
\hline 30 & $27 \pm 3$ & $0.78 \pm 0.08$ \\
\hline 60 & $72 \pm 22$ & $0.93 \pm 0.11$ \\
\hline 90 & $112 \pm 28$ & $1.03 \pm 0.08$ \\
\hline
\end{tabular}

Table 5.

\begin{tabular}{|c|c|}
\hline Samples & $\begin{array}{c}\text { Penetration force } \\
(\mathbf{m N})\end{array}$ \\
\hline A0 & $49 \pm 13$ \\
\hline A1 & $20 \pm 6$ \\
\hline A2 & $11 \pm 3$ \\
\hline$A_{\text {ref }}$ & $5 \pm 1.5$ \\
\hline
\end{tabular}

